\title{
TRuth AND Dependence
}

\author{
JONATHAN TALLANT \\ University of Nottingham \\ DAVID INGRAM \\ University of York \\ Centre for Philosophy of Time, University of Milan
}

\section{Truth-Making: Broad and Narrow}

Truths depend upon what there is. So say many. A significant subset of that group say more; they say that the best way-perhaps the only way-to make sense of the claim that truth depends upon what there is, is to adopt a form of truth-maker theory. In the words of Gonzalo Rodriguez-Pereyra,

The insight behind the idea of truthmakers is that truth is grounded. In other words, truth is not primitive. If a certain proposition is true, then it owes its truth to something else: its truth is not a primitive, brute, ultimate fact. The truth of a proposition thus depends on what reality, and in particular its subject matter, is like. What reality is like is anterior to the truth of the proposition, it gives rise to the truth of the proposition and thereby accounts for it. (2005: 21)

Truth-maker theorists claim that truths require ground; what's true must depend upon what there is. ${ }^{1}$ Typically, truth-maker theory isn't seen as a theory about the nature of truth. Rather, it's seen as a theory about what truths must do. Truths must depend. Relatedly, the claim that truths require 'truth-makers',

1. See also, Rodriguez-Pereyra (2000: 261). Others who speak of truths depending, or requiring that reality be some way such that it enables us to explain why the truths are true, include Bigelow (1988: 121), McFetridge (1990: 42), Molnar (2000: 82), Sider (2001: 36), Daly (2005: 86), Merricks (2007: 30), Schaffer (2010: 317), Schulte (2011: 414), Barker and Jago (2012: 15), Griffith, (2012: 305), Jago (2012: 903), Baron (2013: 2419), Kitamura (2014: 202), inter alia.

Contact: Jonathan Tallant $<$ jonathan.tallant@nottingham.ac.uk $>$ and David Ingram < david.ingram@york.ac.uk> 
that is, some putative ontological grounds, is used as a methodological tool in metaphysics. Put somewhat crudely, fix on what truths there are and locate the truth-makers - if necessary, add to your ontology until you satisfy this demand for truth-makers. ${ }^{2}$ Truth-making is thus at once both narrow and broad. It's narrow insofar as it's not a theory (it's not a claim) about the nature of truth, and yet it's broad insofar as it enables us to determine our ontological commitments. We take this to be a two-part orthodoxy about truth-making.

We reject the orthodoxy on both counts. We begin by arguing that the claim that's often seen as motivating the truth-making project-viz., a truth (any truth) must depend for its truth on something 'outside' itself-should be seen as leading to a commitment to truth having a particular nature. In asserting that truths have natures, we take seriously the charge that this may commit us to truth being a property (or collection of properties) and we respond to recent arguments purporting to show there's no such alethic property. We take this to show that truth-making is broad: contra the orthodoxy, it is (or at least requires us to make) a claim about the nature of truth itself.

Even so, truth-making is narrow; truth-making shouldn't be used as the one methodological tool with which to pursue metaphysics. Or, at least, truthmaking isn't the tool it's typically taken to be. Having said in the opening parts of the paper that truth-making requires us to make a claim about truth's nature, viz., truth depends, we explore the claim that it's of the nature of truth to depend. To do so, we explain what we take to be an appropriate (and well-used) methodology for exploring dependence claims in metaphysics before showing that, from this methodological starting point, we should allow that truth can 'depend' in many ways and this means we shouldn't (perhaps can't) pursue metaphysical inquiry simply as a quest for truth-makers. The orthodoxy fails.

\section{Truth-Making, Dependence, and the Nature of Truth}

The idea that truth must (substantively) depend upon what exists is familiar from truth-maker theory and beyond. As Armstrong has it, in his canonical work on truth-making,

2. Here we have in mind David Armstrong, amongst others. As Armstrong puts it, 'To ask the truth maker question is, I maintain, a promising way to regiment metaphysical enquiry' (2004: 4). And, moreover,

To postulate certain truthmakers for certain truths is to admit those truthmakers to one's ontology. The complete range of truthmakers admitted constitutes a metaphysics ... I think that proceeding by looking for truthmakers is an illuminating and useful regimentation of the metaphysical enterprise, or at least the enterprise of a realist metaphysics. (Armstrong 2004: 23)

Similar ideas, viz., using truth-maker theory as a methodological tool (to determine ontological commitments), can be found in John Heil (2003) and Ross Cameron (2008b; 2008c), inter alia. 
My hope is that philosophers of realist inclinations will be immediately attracted to the idea that a truth, any truth, should depend for its truth upon something 'outside' it, in virtue of which it is true. (2004: 7)

The very same idea has been exploited by truth-maker theorists to move us towards truth-maker maximalism, the view that all truths require truth-makers. The move, described nicely by Cameron (2008a: 412; 2008c: 108), allows that we begin with the claim that at least some truths require (ontological) ground and then asks us to specify the means by which we could restrict that insight. How could we say that some, but not all, truths require ground?

Nonetheless, it's familiar from the literature that truth-making isn't taken to be a theory about the nature of truth. Rather, truth-making is a claim about what kind of connection truths must stand in to the world. For instance, again appealing to Armstrong, we might look to treat the truth-making relation as a connection between true propositions and the world (worldly states of affairs), viz., a relation of "cross-categorial" necessitation (2004: 5-7). But Armstrong is explicit he doesn't think his theory is a theory of truth (2004: 17). This refrain is picked up in several places. Recently, for example, Cameron makes the point strongly:

Truthmaker theory, as I understand it, is not a theory of truth: it is not a theory of what it is to be true, it is solely a thesis concerning what truths are, as a matter of fact, brute.... Our explanation for why a proposition is true and our theory of what it is for that proposition to be true are two separate things, and they need not be related. (2015: 117)

Trenton Merricks puts the point stridently when discussing whether truthmaker theory just is the correspondence theory of truth:

Truthmaker says that every claim has ontological commitments of a certain sort. And Truthmaker catches cheaters who fail to meet those ontological commitments. But none of these claims about ontological commitment amount to-or even look remotely like-a theory of the nature of truth. (2007: 15)

Similar sentiments can be found in Lewis (2001: 278), Beebee and Dodd (2005: 1314), and Bigelow (2009: 396). In fact, we're aware of no truth-maker theorist who makes the case that truth-making is, or carries with it, a particular theory of truth.

But this is puzzling. Let's return to the original insight that true propositions depend for their truth upon something 'outside' of themselves. Indeed, suppose we follow Karen Bennett and agree that truths cannot be allowed to 'float free' of the world. Bennett's view, more fully: 
Truth-or, better, truth-value-depends on being. I find this intuition very plausible. After all, what's the alternative? That truth floats free of being? Surely that's the kind of thought that leads to berets, and a job in a bad Comp Lit department. (2011: 187)

We share Bennett's intuition (and unease of the idea that truth 'floats free'; we remain neutral on the question of berets). We think that this intuition is at the core of what motivates truth-maker theory. Begin with the claim that truths must depend and cash that out as the claim that what's true depends upon what exists. What could be more sensible?3

Nonetheless, we think these positions-viz., all truths have truth-makers, but truth-maker theory itself doesn't offer a theory of truth-create an interesting and troubling tension. We ask, if Truthmaker (or something like it) is true, why should it be the case that truths don't float free of being? Why can't a truth float free in this way? Why can't a truth fail to depend upon the world?

One answer-our preferred answer-is that it's at least part of the nature of what it is to be a truth, that is, a true proposition, to depend upon the world. That may seem somewhat abstract. To get a feel for our claim, compare it to some others. First, Aristotelian universals cannot fail to be instantiated in the world. This is (at least in part) because they have the natures that they do. It's of the nature of an Aristotelian universal to exist only if instantiated. Next, coloured objects reflect light, where light is present. This is (at least in part) because it's of the nature of a coloured object to reflect light, where light is present. Last, massive objects curve space-time. This is (at least in part) because it's of the nature of a massive object to curve space-time. All well and good.

We simply claim that truth is the same (or at least relevantly similar). We make no claim to exhaustively characterise the full extent of the nature of truth, but we think the insight that truth-maker theorists are reaching for here is that it's (at least a part) of the nature of a true proposition to depend. It's (at least in part) because they have such natures that truths exist only when they depend. If that's right, then we have a tension. If truths need to be grounded, this is so because of their natures. A nature is a property-at least, so we claim. Thus, truthmaker theory commits us to a theoretical claim about truth: it has a naturepartly constituted by a property, depending.

Let's flesh this out a bit. Why think there's such a property, as opposed to leaving this talk of nature as it is? Two reasons. First, take an example: it's of the

3. Of course, such intuitions aren't taken to be compelling by all. Matthew McGrath (2003: 684-685), for instance, would describe the kinds of truth-making we explore as 'existential' (as opposed to 'non-existential') and thinks that the pursuit of such existential truth-makers for all (true) propositions is folly. See also, Melia (2005). This is well and good. We don't say that everyone agrees with the orthodoxy; we merely argue that there is one. 
nature of electrons to be negatively charged. One natural reading of that is electrons instantiate a property, being negatively charged. It's part of what it is to be an electron to instantiate that property. We can then speak of the property 'being an electron'; it's partly constituted by being negatively charged. Another example. It's of the nature of a quark to have a specific spin value. A natural reading: quarks instantiate a property, having a particular spin. It's part of what it is to be a quark to instantiate that property. We can speak of the property 'being a quark'; it's partly constituted by having a particular spin. Now, to the truths. It's of the nature of truths to depend. A natural reading: true propositions instantiate a property, depending. It's a part of what it is to be a truth to instantiate that property. We can speak of the property of 'being a truth'; it's partly constituted by depending. So, truths (like electrons and quarks) have natures; and it's of the nature of a truth (any truth) to depend. This nature is partly constituted by a property, depending. And, as we shall see, even this modest claim (that truth-maker theorists offer a partial theory about the nature of truth) has consequences for the wider debate. Second, suppose truth just has (rather than is) a nature. If having a nature is a matter of instantiating a property (like depending), then we'd better be clear on what kind of thing truth is (for only things can instantiate properties). Beyond itself being a property, it's hard to see what truth would be. And, in any case, even if there were some answer to that question that didn't treat truth as a property, but as a kind of abstract particular, that would still defeat the claim that truthmaker theory doesn't commit us to a theory of truth. So much the worse for the orthodoxy. 4

In any case, that's our preferred answer to the question of why truths depend. There's a property, being true, and that property is itself at least partly constituted by the property depending. (It may be the case, we suppose, that 'truth' is a complex property that has 'depending' as a part.) How can we persuade you it's the right answer? Well, let's ask the maximalist, "Why do all truths depend?" Without an answer, matters look mysterious: truths depend, but why? There's no answer. They just do. And with this line of response, we worry all we're left with is an airy wave of the hand: "Truth depends, because it does." (We concede to the maximalist that we have an intuition that truths depend. But we must separate the questions of why to think truths depend from why truths do depend. We're interested in the latter. It would be good, all things considered, to answer such a question.)

How else might we answer the question? We can't think of many options. One option might be to say that truths depend because some theory of truth is correct and it's a requirement of that theory that truths depend. But we know of

4. From here on, we run together talk of 'truth having a nature' and 'there being a property of truth', since, as argued, both claims express the same metaphysical commitments. 
no theory that delivers this result (and, even if it did, such an answer would have us give up the orthodoxy). The deflationary theory of truth doesn't require it. Deflationism merely requires satisfaction of the T-schema: ' $\langle p\rangle$ is true iff $p$ '. The correspondence theory of truth doesn't require that truths depend either; it says truth is correspondence to a fact, but correspondence isn't dependence. Another option is to assert that 'truths depend' is just a brute fact about truths. On this account, there's no more to be said. That, we think, is no kind of answer at all. It doesn't explain why truths depend, it merely asserts they do. So, on the assumption we should answer such a question ("Why do truths depend?"), we need to explain why truths depend. And we really think this question is pressing: either it's a mysterious, unexplained fact about reality as to why truths depend, despite not being in their nature to do so, or else truths depend because of the kinds of thing they are. We prefer answers, where answers are available, especially when the questions are pressing. And so, we say, truths depend because of the kinds of thing they are, with the nature they have.

\subsection{Dependence Reconsidered}

Here's a worry for us. Consider ordinary physical objects: tables and chairs, cats and dogs, etc. It's plausible enough, we assume, that such objects depend upon their parts. Nonetheless, there may be no good answer to the question, "Why do physical objects depend upon their parts?" That question looks structurally parallel to ours ("Why do truths depend?"). Now, if there's no good answer to the question about physical objects, why think there's a good answer to our question about truths? Our response has two independent parts, which we take in turn.

Part one: there may be an answer in the case of physical objects. Let's begin by thinking about dogs. What's essential to some entity $x$ being a dog? We're not sure exactly (lacking the right degrees), but we suppose it's essential to $x^{\prime}$ s being a dog that $x$ has the right kind of DNA (absent that, we don't think $x$ would be classified as a dog). So, x's being a dog depends upon $x$ having the right kind of DNA. But, having the right kind of DNA depends upon having parts - one can only have DNA, if one is spatially extended, and one can only be spatially extended if one has parts, after all. 5 That being so, x's being a dog at least partially depends upon x's having parts. And that's our explanation. It's essential to $x$ being the very kind of thing that a dog is, to having the nature of dog-hood, that $x$ has the right DNA, and it's essential to $x$ being the kind of thing that has DNA is that $x$ has parts. Note: our explanation stems from the natures of dogs and DNA. The natures fix the dependence (grounding) claims. This is our first reply to the worry. Where physical objects do depend upon their parts, our explanation of

5. We assume a rejection of extended simples. 
why this is so turns on the natures of the entities concerned. And, that being so, the case of physical objects is structurally parallel with the case of truth.

Part two: truth-maker theorists tell us that all truths depend. Structurally, that is, they tell us that "All Fs G." We then ask, "Why do all Fs G?" The imagined response says that if we're unable to say why all Fs $\mathrm{G}$ in the physical case, our position is no better. But we demur. Not all physical objects are dependent. Thus, in the case of physical objects not all Fs G. At least, some claim not all physical objects depend. For instance, Jonathan Schaffer (2010) relies on this when motivating Priority Monism; the view that exactly one physical object is fundamental, and doesn't depend for its existence upon anything else. Similarly, one of us (Tallant 2013) relies on this when arguing against views that treat any element of reality as fundamental. If not all physical objects depend upon their parts, then it's not true that, qua physical object, a physical object is the kind of thing that depends.

What of it? The challenge to truth-maker theorists, we submit, is to explain why all truths depend. It's a striking coincidence if they just do; the coincidence cries out for an explanation. Now, if not all physical objects depend, we have no need for an explanation in the case of such objects-there's no coincidence to be explained. We may have some explanatory duties to discharge, to be sure, but the details of those will turn on the precise nature of the grounding claims being made. Given both parts of our response, we think we can handle the worry raised at the start of this section.

\subsection{The Consequences of Dependence}

With that in hand, we'll now explore some of the consequences of saying truths have a nature and that it's at least a part of the nature of truths to depend. We take it that in most normal cases a nature will be equated with a property of some kind or other. Thus, if a table has a specific nature (e.g., it's brown, smooth, etc.), then this consists in the table exemplifying some property or properties. And, simply put, we see no reason to think the case of truth is different. Truths have natures; truths are the kinds of thing that depend. Being the kind of thing that depends is a property. In that case, what it is to be a truth is to have a very specific nature, a part of which is being the kind of thing that depends.

This is striking. There's no shortage of those in the literature who claim truth-making is consistent with deflationary theories of truth (e.g., Cameron 2015: 117). But if we're right, then it's not. Truth-making isn't consistent with deflationism, for truth has a nature that outstrips the T-schema. And, in fact, we're in a position to show how certain arguments fail. In particular, we respond to two arguments used recently by Jamin Asay (2014), arguments that purport to demonstrate the adequacy of minimalism about truth. 
Asay's first argument turns on the motivation for thinking there's a truth property. When we posit sparse properties, Asay claims, we do so in response to at least one of three concerns: to explain resemblance, to play some causal role, or to play some truth-making role. (We would add, we also posit properties to play an explanatory role, even if no truth-making role is required.) Asay asserts that a truth property can do none of these (2014: 157).

Given what we've said so far in this paper, how do we respond? First, consider a variation of the argument offered in Section 2.1. The maximalist has it that all truths depend. This is something that all truths have in common. In contrast, we argue (in Section 2.1) that it's not of the nature of all physical objects to depend. We said it's of the nature of truths to depend. In that sense, there's a unified class of entities, the truths (true propositions), whose resemblance is to be accounted for. A truth property accounts for this resemblance. All truths have this feature; they all depend. Second, we need the truths to have natures in order to account for why they depend. This is a distinctive theoretical role that the truth property plays. We must offer some theoretical explanation for why the truths depend. Our explanation: because it's of their natures to do so. Thus, Asay's first argument fails. There are at least two reasons to think there's some theoretical need for a property of truth.

Asay's second argument against a truth property turns on the alleged redundancy of any such property in the context of truth-making. To see the argument, consider (e.g.) the true proposition, $<$ Samwise is brave $>$. Given orthodoxy about truth-making, we can say <Samwise is brave > is made true by the existence of a fact, for example, that Sam instantiates the property being brave. Truth-maker theorists say that if the fact exists, the proposition is true. What's required, then, is the existence of a particular, Sam, a property, being brave, and their union. What's not required is the existence of a further property that attaches to the proposition, namely being true (2014: 158). The truth property is redundant in this context. All the work is already done. That's not to say the proposition doesn't instantiate being true, only that the truth property doesn't do any work in the story of how the proposition gets to be true.

There are reasons, Asay thinks, to be worried about accepting that being true is involved in the story of how propositions are 'made true'. It seems there would be no need for any property besides truth if we embraced a 'substantivism' about truth. If, rather than the truth-making story, all we need for the truth of $<$ Samwise is brave $>$ is the truth property attached to the proposition, then Sam and being brave are themselves redundant. The proposition and the truth property do all the work themselves. But, Asay worries, that's plainly absurd. Truth can't work like that. The truth of $<$ Samwise is brave $>$ is explained by Sam exemplifying being brave; it's not explained by the proposition exemplifying being true. Truth doesn't work well on its own. However, if truth can't do that labour 
by itself -if all the explanatory work is done by other entities, like Sam and being brave - then truth is a metaphysical deadbeat with nothing to contribute (2014: 159). Our metaphysical politics has us frown on such deadbeats.

But, contra Asay, this can't be right if our account is correct. We say it's of the nature of truths to depend. So a truth property can't do the work by itself, for its nature is such that it must depend. Absent something upon which to depend (e.g., something like a worldly fact that unites Sam and being brave in the case of $<$ Samwise is brave>), no proposition can instantiate the truth property. This follows simply and straightforwardly from our claim that it's of the nature of truths to depend. By way of analogy, just as the property being a brother can't be instantiated in the absence of a sibling, so being true can't be instantiated in the absence of something to ground the truth. So, as we have it, Asay's argument against a truth property fails. Truth is no deadbeat.

All things considered, we think we have reason to accept a truth property and that adopting truth-maker theory commits us to at least a partial claim about what kinds of features that property has. We think truth-maker theory thereby commits us to a metaphysically substantive property of truth. Thus, truth-maker theory is broad; it commits us to truth having a nature and, thus, to a theory about the nature of truth. ${ }^{6}$ With that in hand, we now wish to divert to the promised discussion of dependence.

\section{Dependence and Method}

We say truth-maker theory is broad; it commits us to truth having a nature. We say that it's of the nature of truths to depend. (That was Section 2.) But we've said nothing, so far, about what it is to depend. There's reason for our silence up to this point: dependence is complex and varied. There is, we think, no single monolithic notion of dependence. Dependence comes in many kinds. Of course, this claim isn't original to us. To get a feel for some of the moves made in the literature, here we survey two proponents of the view that dependence comes in many flavours, E. J. Lowe and Kathrin Koslicki.

We begin our survey with a range of different kinds of dependences identified by Lowe (2010). Lowe's work includes many rich discussions of different

6. In sum, the deflationary theory has most often been presented with the help of a schema: $\langle p\rangle$ is true iff $p$. We can formulate deflationism as the view that, roughly, instances of this 'Tschema' capture everything significant to be said about truth. Fine. But if that's all of significance that can be said about truth, we don't have the resources to explain why it is that truths cannot 'float free' of being; there need be no presupposition that what sits on the right-hand side of the bi-conditional is ontologically committing, nor any presupposition that the right-hand side brings with it a commitment to grounding. That being so, it seems there's something about truth's nature that outstrips what is specified by the T-schema. 
kinds of dependence (see, e.g., 1998; 2006; 2013; for an opinionated survey, see Koslicki 2013). Here, we focus on various ontological dependences; we say nothing about causal, logical, or probabilistic dependence nor do we say anything of supervenience. But, we take it, the mere fact there are other such notions of dependence further serves to make our point: dependence is many and varied; it comes in many kinds. Lowe (2010: Section 1) identifies three existential dependences, 'rigid' (EDR), 'non-rigid' (EDN), and 'generic' (EDG), which he provisionally defines as follows:

(EDR) $\quad x$ depends for its existence upon $y={ }_{\mathrm{df}}$ Necessarily, $x$ exists only if $y$ exists.

(EDN) $\quad x$ depend $_{\mathrm{n}}$ for its existence upon the $F={ }_{\mathrm{df}}$ Necessarily, $x$ exists only if the $F$ exists.

(EDG) $\quad x$ depends $_{\mathrm{g}}$ for its existence upon $F \mathrm{~s}={ }_{\mathrm{df}}$ Necessarily, $x$ exists only if some $F$ exists.

As Lowe (2010: Section 1) explains, (EDR) is equivalent to, 'necessarily, if $x$ exists, then $y$ exists'. That is, the rigid existential dependence ('dependencer ${ }_{\mathrm{r}}$ ) of $x$ upon $y$ amounts to a strict implication: $x^{\prime}$ s existence strictly implies $y^{\prime}$ s existence. It's easy enough to give an example. Consider Samwise and \{Samwise\}, his singleton. It's true that, necessarily, if \{Samwise $\}$ exists then Samwise exists. As a consequence, we may say that $\{$ Samwise $\}$ rigidly existentially depends upon Samwise.

The rigid notion (EDR) can be contrasted with a non-rigid variant (EDN). Here we have the same sort of equivalence. (EDN) is equivalent to, 'necessarily, if $x$ exists, the $F$ exists'. But 'the $F^{\prime}$ is suitably general so as to denote different entities in other possible worlds. Again, it's easy enough to give an example; Lowe's own will suffice:

a material object $\mathrm{x}$ depends $\mathrm{s}_{\mathrm{n}}$ for its existence upon the matter composing $x$, even though it might have been composed of different matter, because in every possible world in which $x$ exists the matter composing $x$ in that world exists in that world. (2010: Section 1$)^{7}$

The third and final notion of dependence drawn from Lowe (2010), that is, 'generic existential dependence' (EDG), is equivalent to, 'necessarily, if $x$ exists, some $F$ exists'. Here's a simple example: a material object will generically existentially

7. This isn't the non-rigid ontological dependence discussed by Joseph Diekemper (2015: 6566) or David Ingram (2016: 2873-2874), inspired by Lowe (2006). Diekemper's and Ingram's notion is yet another way to characterise how an entity may ontologically depend. (We introduce this notion of dependence in a little more detail in Section 5.) 
depend ('depend $\mathrm{g}_{\mathrm{g}}$ ) upon its parts for its existence; it can survive a loss of some parts, but cannot survive the loss of all parts simpliciter.

In addition to the three notions of existential dependence just defined, we find a notion of 'identity dependence' (ID) in Lowe (2010: Section 4):

(ID) $\quad x$ depends for its identity upon $y==_{\mathrm{df}}$ There is a function $f$ such that it's part of the essence of $x$ that $x$ is $f(y)$.

Here's an example of this kind of dependence, borrowing again from Lowe. Since the identity of a marriage (some event, $x$ ) depends on the identities of the two people being married (some persons, $y$ and $z$ ), $x$ is necessarily identical with 'the marriage of $y$ with $z$ '. The required function $(f)$ in this case is the 'marriage with $z^{\prime}$ function from persons (e.g., $y$ ) to events (e.g., $x$ ). (I.e., the marriage of Sam and Rosie, e.g., depends for its identity upon Sam. There's a function, viz., the 'marriage with Rosie' function from Sam to the event, their marriage.)

This also enables us to answer the question, "Why think there's more than one kind of dependence?" Our answer: because these different cases exhibit a different kind of dependence; the dependences each have a different modal profile. ${ }^{8}$ In general, though, we think accounts of dependence relations should be sensitive to the kinds of dependence we find in the world; the kinds of dependence Lowe purports to identify. If accounts of dependence aren't appropriately sensitive, we fail to see that these accounts of dependence can be viewed as successful. Failing to recognise the difference in kind between different types of dependence is, we submit, akin to stipulating that, when considering the metaphysics of relations, all relations are two-placed and ignoring all cases of relations that differ with respect to their adicity. That's just bad metaphysics.

In addition to the notions of dependence drawn from Lowe (2010), we can also see a range of different kinds of dependence described by Koslicki (2012; 2013). Here's our second survey (in part, to demonstrate Lowe's approach isn't idiosyncratic). We focus on two kinds, 'constituent' (CD) and 'feature' dependence (FD). Koslicki introduces and provisionally analyses each as follows:

(CD) $\quad x$ is constituent dependent on $y$ (or the $y$ s) iff:

$y$ is an essential constituent of $x$ (or the $y$ s are essential constituents of $x$ ). (2012: 205)

8. See Lowe (2012) for discussion and arguments motivating the rejection of a monolithic approach to dependence. 
(FD) $\quad x$ is feature dependent on $y$ (or the $y$ s) iff:

(i) $y$ is a constituent in a real definition of $x$ (or the $y s$ are constituents in a real definition of $x$ ), and (ii) $x$ corresponds to a feature of y. (2012: 209)

Koslicki describes (CD) and (FD) as 'essential dependences'. Essential dependences are those in which the relation of ontological dependence turns on matters concerning a thing's essence and its "real definition" (Koslicki 2012: 197). Before explaining (CD) and (FD), it's useful to review some unexplained technical notions in the forefront of Koslicki's analyses, specifically 'real definition' and 'essential constituency'.

For Koslicki, a real definition

is expressed by a statement containing a noun-phrase standing for $\Phi$, the entity to be defined (i.e., the definiendum), together with a noun phrase standing for $\Psi$, the entity or entities in terms of which $\Phi$ is to be defined (i.e., the definiens) (2012: 197)

and, further, "these two expressions are connected by a relational term of some kind which stands for the definitional relation holding between the definiendum and the definiens" (2012: 197). Koslicki identifies constructions, such as 'To be $x$ is to be $y$ ', as typical ways of attempting to formulate real definitions (in English). So, for example, we might say, 'To be a man is to be a featherless biped with broad flat nails.' In doing so, we offer a real definition of 'a man' (a noun-phrase, our definiendum) as a 'featherless biped with broad flat nails' (another noun-phrase, our definiens). The criterion of success for such definitions, for Koslicki, is as follows:

A statement that purports to express a real definition thus is successful, according to the current approach, if it not only uniquely identifies and delineates the entity to be defined, but also states what it is to be the entity in question, i.e., if it is explanatory of the essential nature of the definiendum. (2012: 200)

Thus, our definition of 'a man' wouldn't count as successful (qua real definition) since being a featherless biped with broad flat nails doesn't state what it is to be a man.

Building on this way of understanding 'real definition', we can say something about Koslicki's other notion: essential constituency. Koslicki defines 'essential constituent' as: $x$ is an essential constituent of $y$ iff: (i) $x$ is a constituent in a real definition of $y$, and (ii) $x$ is a constituent of $y$ itself (2012: 203). An example: 
Samwise is an essential constituent of his singleton, \{Samwise\}. The real definition of \{Samwise $\}$ includes Samwise as a constituent. A definition that 'uniquely identifies and delineates' Samwise's singleton, and states what it is to be $\{$ Samwise\}, must include Samwise as a constituent. And Samwise is a constituent of \{Samwise\}. Indeed, Samwise is a member (the sole member) of that set. Note that set-membership is only one plausible way to understand '.. . is a constituent of ...' in the definition of essential constituent; other ways include parthood, constitution, and so on.

With this background explained, we can say something about constituent dependence (CD) and feature dependence (FD). Recall, (CD) states that $x$ is constituent dependent on $y$ iff $y$ is an essential constituent of $x$. So, returning to Samwise and singleton, $\{$ Samwise $\}$ is constituent dependent on Samwise. More generally, though, this notion of constituent dependence can be used to characterise the dependence relation between any complex entity and its (essential) constituents. Consider any (mereologically complex) material objects, this notion of constituent dependence seems to characterise the sense in which such objects ontologically depend on their proper parts (Koslicki 2012: 205-206). Next: feature dependence, a distinct kind of (ontological) dependence. Recall, (FD) has it that $x$ is feature dependent on $y$ iff (i) $y$ is a constituent in a real definition of $x$, and (ii) $x$ corresponds to a feature of $y$. It's clear that \{Samwise\} isn't feature dependent upon Samwise. There's no feature of a singleton that its member corresponds to, even taking 'feature' loosely to denote any way the set is. By contrast, we can say that a smile is feature dependent upon a mouth (Koslicki 2012: 210). There are other examples of feature dependence at work that may be of greater metaphysical significance. Consider, for example, the way a trope depends upon the object exemplifying it. We might say, following Koslicki, that a trope "corresponds to a feature had by an object" (2012: 208), and is thus feature dependent upon that object (rather than constituent dependent upon it). This isn't an exhaustive survey. But it does give a sense of some different kinds of (metaphysical) dependences being discussed in the literature.

Why bother with these surveys? What's noteworthy, we think, is the methodology deployed in each case and in these debates. Crudely, the idea pursued is that we begin with how the world is and then describe an appropriate range of kinds of dependences that hold. To illustrate, consider an example. Begin with a loose notion that some objects depend. Well and good. Then, note that heaps are objects about which it seems correct to say that they depend. Intuitively, a heap depends upon its parts. Let's try to make sense of that claim. In exploring the world, we recognise heaps survive a loss of parts. Now, contrast this kind of dependence with the connection between set and member. Clearly, the relation is very different. The relation of dependence between a singleton and (sole) member must be different from the relation of dependence between a heap and parts 
that compose it, because neither the singleton nor its member can exist without the other. ${ }^{9}$ What have we learned? Plausibly, that these are different kinds of dependence. But, more pressingly, that the methodology we are interested in here is one that begins with the world and then locates the kinds of dependence that are in play. We begin with how the world is and then describe an appropriate range of kinds of dependences that hold.

\section{Truth and Dependence United}

We now want to bring together two distinct claims. One substantive claim about truth: truths depend. And one methodological claim, drawn from the literature about dependence: begin with how the world is and then describe an appropriate range of kinds of dependences that hold. If these claims are brought together, then, we submit, it's going to be very hard to rule out particular first-order positions in metaphysical inquiry using a truth-maker argument. The general (and at this stage somewhat sketchy) shape of our concern is this: suppose we start out with particular ontological commitment, $O$, and a set of truths, $\left\{T_{1}, T_{2}, \ldots\right\}$. Each member, $T_{n}$, of this set must depend, of course. Our opponent, an orthodox truth-maker theorist, will argue that if $O$ doesn't ground the truth of each of $\left\{T_{1}, T_{2}, \ldots\right\}$, (where 'dependence' is understood in this case as a primitive and unanalysable, monolithic kind of relation; a truth-maker relation), then so much the worse for the theory that commits us to $O$. But, say we, if we're at liberty to sketch a fully appropriate range of dependences, then we can develop a range that will allow us to agree that all truths depend, and will allow us to do so without adding to $O$. If we're right, there's no way to deploy truth-making as a single, unifying way in which to approach metaphysical inquiry. ${ }^{10}$ Rather than looking for truth-makers, one may simply look for a different kind of dependence. In demonstrating this, and exploring the consequences, we draw on two distinct (though connected) literatures: on presentism and truth-making (Section 4.1), and on the problem of negative existential propositions and truth-making (Section 4.2).

9. Indeed, the reason we think that positing only one kind of ontological dependence is wrong is that it fails to respect the different dependence relations in which objects stand to one another. See, e.g., Lowe (2012) and Tallant (2015) for discussion and defence of these conceptions of dependence.

10. On this point, we extend an idea due to Aaron Griffith (2014), who argues that truthmaking is correctly seen as a species of grounding. We agree, but (as should be clear), we seek to add that there are a variety of species of truth-making/truth-grounding. Here our proposal parallels Griffith's (2015b) development of a 'pluralist' theory of truth-making. 


\subsection{Presentism, Truth, and Dependence}

Presentists believe that only present entities exist. They also accept there are truths about the past, for example, <Boudica was fierce $>$. But, if only what's present exists, asks the truth-maker theorist, what makes true that proposition about the merely past entity? No present thing appears to ground its truth, and merely past entities don't exist. There seems to be a lack of truth-makers. The normal response in the literature, at this stage, is to inflate presentist ontology; to add presently existing resources as truth-makers for various propositions about the past. But not everyone takes this approach. We pursue one particular species of response to this 'truth-maker problem' facing presentism - a 'nefarious' response. And, to begin, we borrow the initial mode of presentation from an earlier temporal part:

[The nefarious] use the language of truth-maker theory, without paying any price in the coin of ontology. They say things like: '<Caesar crossed the Rubicon> is made true by the fact that Caesar did cross the Rubicon'. But when pressed to tell us what 'Caesar did cross the Rubicon' consists in, they demur. 'Do not talk of existing truth-makers', they tell us. 'Rather', they say, '<Caesar crossed the Rubicon> is true because Caesar crossed the Rubicon. This is a tensed truth about the world, and there is no explanation for its truth to be given in terms of ontology'. In perfectly general terms, all that nefarious presentists think we can say is that $<\mathrm{It}$ was the case that $p>$ is true, because it was the case that $p$. (Tallant \& Ingram 2015: 356)

Unpacking what it is to be nefarious, we claimed that nefarious presentists endorse two claims: (1) truths about the past are expressed using primitive and unanalysable tense operators, and (2) such operators don't pick out an ontological category or aspect of reality (Tallant \& Ingram 2015: 356). So, one of us (Tallant 2009-himself a nefarious rogue) claims that ' $<$ It was the case that $p>$ is true, because it was the case that $p^{\prime}$, the 'was' is primitive and unanalysable, and it doesn't pick out any ontology whatsoever (Tallant 2009: 424; Tallant \& Ingram 2015: 356). Truths about the past are true because of how things were.

We argued (2015) that presentists should favour a nefarious approach over an 'upstanding' response. Upstanding presentists locate presently existing truth-makers for truths about the past; they say that truths about the past are true because of how things are (i.e., made true by present truth-makers). But they must also say that how things are now (viz., the truth-makers) is fixed by how things were-or else the truth-makers could get the 'wrong results'. As we put it, "upstanding presentists must say their presently existing truth-maker, $E$, 
for some truth about the past, exists because of the past existence of some other entity, $e^{\prime \prime}$ (2015: 362, our italics). The way the world was is such that the present truth-maker, $E$, must exist, and it's in virtue of $E$ that a given truth about the past is true. To illustrate, consider a true past-tensed proposition about a non-present entity, <Philippa was virtuous $>$, and its present truth-maker. What blocks the possibility of a scenario in which it's true that Philippa is virtuous but never true afterwards that Philippa was virtuous? Presumably, there's a connection between how things were in the past (Philippa being virtuous) and the presentist's present truth-maker for $<$ Philippa was virtuous $>$. But if presentists allow this 'fixing' between the past (Philippa's having been virtuous) and present (the truth-maker, $E$ ), why postulate present truth-makers at all? If presentists are willing to say that the way things were fixes which truth-makers exist, they should be willing to say, instead, that the way things were fixes the truth of (present) propositions about the past. This is the nefarious road.

The strategy we deployed has a particular shape. Begin with a presentist ontology, consisting of only present entities. On the ontologically inflationary upstanding move, the putative present truth-makers exist because the past was some way, and the truths about the past are true because those present resources exist. The nefarious cut out the middle-man. How things were grounds how the truths are; truths about the past are true in virtue of how things were. This is a kind of dependence. We dub it 'tensed dependence'.

To repeat, begin with how the world is and then describe an appropriate range of kinds of dependences that hold. If that methodology is good enough in the debates about dependence, generally, we see no reason why it might not sensibly be invoked here, as well. But notice: if that's right, then it's now not obvious how to pin a truth-maker objection on presentism. Sure, truths depend. But methodologically we proceed by describing how the world is and then describing a full and complete range of dependences that truths have. In this case, the dependences take something like the following form: necessarily, if the world was thus-and-so, then it's now true that the world was thus-and-so. There is, then, no truth-maker objection to presentism. We do away with it as soon as we recognise that the ways that truths can depend are many and varied.

\subsection{Negative Truth and Dependence}

Structurally, we want to make the same move here that we make in the presentism and truth-making literature, but apply it to the issue of true negative existential propositions-propositions that deny the existence of some entity or other (e.g., $<$ there are no hobbits $>$ or $<$ there are no arctic penguins $>$ ). As in the presentism literature, the dialectic is as follows. We begin with a rough sense of what exists 
(shoes, ships, sealing wax, etc.), driven perhaps largely by empirical concerns. We then note there's nothing that looks apt as ontological grounds for the truth of true propositions about what there isn't. What 'makes true' <there are no arctic penguins >? It won't be the arctic; the arctic is compossible with penguins (and it won't be other penguins, for the same reason-they, too, are compossible with arctic penguins). No obvious entities come to mind to do truth-making work. From there, we might look to inflate our ontology and posit myriad 'absences' or 'negative facts' (or, perhaps, a single 'totality fact') to ground the truth of true negative existentials, for example, the (negative) fact that there are no hobbits would serve as a truth-maker for $<$ there are no hobbits $>.{ }^{11}$ Call that additional ontology, $D$.

Now, once again, we must rule out the 'wrong results'. In this case, such wrong results would be the existence of (say) both hobbits and the entity that is the reified absence of hobbits. Clearly, no such scenario is possible; we can't have a world that includes hobbits and the absence of hobbits. That being so, that there are no hobbits must be understood as fixing (or determining) that $D$ (our reified absence) exists - to rule out these wrong results. And, if it can do that-if there not being any hobbits can fix that $D$ exists - then we see no reason that it might not, instead, fix that certain truths are true. Again, $D$ exists because there are no hobbits. ${ }^{12}$ And if $D$ exists because there are no hobbits, we may say that $D$ depends for its existence on there not being any hobbits. So, why not simply remove this extra step? Why not say <there are no hobbits $>$ depends for its truth on there not being any hobbits? If the move is viable in the presentist case, and we think it is, then it's viable here too-the cases are parallel. ${ }^{13}$

That being so, we can say there's a novel kind of dependence here. The form of that dependence? Necessarily, if there are no hobbits, then <there are no hobbits $>$ is true. Our true negative existential, <there are no hobbits $>$, is true in virtue of there being no hobbits. We dub this 'negative dependence'. We began by noting how the world is, viz., there are no hobbits and <there are no hobbits $>$ is true, and from there describe the dependences that hold. Again, this is no more than another application of the methodology at work in the dependence literature. If the methodology is viable within that literature, and we wish to say what's true

11. See, e.g. Martin (1996) and Kukso (2006) on absences, Barker and Jago (2012) on 'fullblooded' negative facts, and Armstrong (1997: 196-201; 2004: 54-82) on the totality fact.

12. We have little time for the idea that hobbits don't exist because there exists an absence of them. This has the order of explanation the wrong way around. The correct order of explanation, we submit, is that 'there is an absence of $x^{\prime}$ is true because there are no $x \mathrm{~s}$.

13. Of course, if the move isn't viable, both maximalists and presentists face a problem: it's true that the additional ontology, $D$, exists because of or in virtue of something that doesn't exist (hobbits, dinosaurs, etc.). If we can't have these in virtue of relations, in the absence of one of the relata, no such truth-making story is adequate. Thus, we argue, it won't do for our opponent to simply insist that any such in virtue of relation commits us to the existence of both relata. 
depends on something 'outside' of itself (as per Armstrong, inter alia), we may deploy the methodology to generate the kinds of result we have here. ${ }^{14}$

\subsection{Consequences}

We think this generalises. For any domain, begin with what there is. Of course, we should then say that truths depend, but highlight the versatility of the different kinds of dependence we can appeal to. Whilst we can't prove matters are so, we simply can't see any reason to think the result won't generalise. And, if we're right about that then it's only a short step to seeing why we can't use truthmaking as a tool with which to pursue metaphysical inquiry. Rather than using the demand for truth-makers to force ontological commitments, it's easy enough (as we've shown) to simply multiply the number of kinds of dependence that are in play. But, more cautiously, we're not in fact, multiplying the number of kinds of dependence. Those connections are there already. We aren't inventing substantive modal or non-modal connections. We're using them. We're multiplying the number of kinds of dependence in play in the metaphysics. (We're not multiplying the kinds of dependence in the world.)

To see this, note that both nefarious and upstanding presentists agree that something exists in virtue of how the world was: the upstanding presentist says that what exists in virtue of how things were is some additional ontology; the nefarious presentist says that it's a truth. But, regardless, all involved agree there's a (trans-temporal) dependence. We just want to put it to truth-making work. Similarly, both upstanding and nefarious approaches to negative existentials posit a dependence. The upstanding approach says the reified absence of hobbits exists in virtue of there being no hobbits; the nefarious approach says the true proposition exists in virtue of there being

14. Our end position - different truths might depend upon what there is in different waysis familiar from the literature. Griffith (2015a) argues for such a position. However, our strategies are markedly different. Griffith argues that we should adopt this position because it facilitates a straightforward solution to the problem of negative existentials. We suggest, here, that truthmaker maximalists are already committed to a relevant notion of grounding (additional ontology, $D$, exists in virtue of there not existing some entity) and that, as such, we have no need to posit $D$; simply say that $<i t$ 's not the case that $x$ exists $>$ is true in virtue of there not existing some $x$. The key selling point of Griffith's model (in his own words) is that,

it allows us to respect the intuitive differences between positive and negative truths and articulate the way in which negative truths are made true by entities, while releasing us from the need to postulate controversial truthmakers to necessitate negative truths. (2015a: 318)

In contrast, we say that by the maximalist's own lights there's no need to posit the controversial truth-makers. 
no hobbits. But again both agree: there's a dependence. And, again, we put it to truth-making work. ${ }^{15}$

Our approach (in contrast with the upstanding) requires no further ontological commitments. We don't inflate ontology to meet truth-making commitments. To the extent we prefer ontological parsimony in our metaphysical theories, our approach has at least that much to recommend it. (Lovers of Quinean 'desert landscapes' may find something attractive here. We simply use the multiplicity of kinds of dependences to act as a cool breeze, enhancing our experience of the otherwise arid desert.)

\section{Concerns}

We must now deal with some concerns for our nefarious picture of dependence. We focus on three: nefarious dependencies aren't really dependencies (Section 5.1); there are some insuperable concerns generated by intuition (Section 5.2), and, we're committed to a troubling 'alethic pluralism' (Section 5.3).

\subsection{No (Nefarious) Dependence}

We say there are a variety of dependence relations in the world and that such dependences can be put to work. As things stand, we anticipate the following objection. In brief, the dependence between truth and world described is no kind of dependence at all. Dependences are existence-entailing relations which only connect existing relata. The non-existent (non-present) Philippa or non-existent hobbits, for instance, can't be so related. Or so says our imagined opponent.

First, it's useful to review our (2015) response to similar concerns. The upstanding truth-maker theorist inflates their ontology to meet certain demands for truth-makers; upstanding presentists, for example, postulate a present entity

15. Some truth-maker theorists, such as Armstrong (2005) and Cameron (in press), motivate their upstanding approaches by pointing to the fact positing one truth-making relation (and one way for propositions to be 'made true') is economical. Armstrong makes the point as follows:

[Would] not Truthmaker Maximalism give a considerable theoretical economy ... by making every truth require a truthmaker? Given Maximalism, one does not have to have at least two theories of the nature of truth, and is this not an economy? (2005: 272)

We like Armstrong's point, but don't see that it threatens our position. Our opponent might insist we multiply dependences beyond necessity, but, as we've explained, we don't think we do. The dependences are already present. In our nefarious treatment of dependence, we merely put them to work. We have one theory of truth: truths depend. And we have no more kinds of dependence than our opponent. Again, we merely put them to work. 
$(E)$ as truth-maker for <Philippa was virtuous $>$. But now consider the supposed 'connection' between Philippa's having been virtuous and $E$. The connection isn't existence-entailing - presentists deny the existence of the past event, Philippa being virtuous. But it certainly seems to be a kind of dependence. To provide the right truth-makers for truths about the past (to avoid the 'wrong results'), upstanding presentists must say the present truth-maker exists in virtue of the world having been some way (Tallant \& Ingram 2015: 365 ). This is dependence, plain and simple. The fact such a relationship isn't existence-entailing shouldn't trouble us.

Moreover, we look to challenge the general claim (from our imagined opponent) that all dependences are existence-entailing. One approach is to mine the literature for examples of non-existence-entailing dependences. Recently, one of us has offered a form of non-rigid ontological dependence, which can be characterised as follows:

(NRD) $x$ depends (non-rigidly) for its existence upon $y==_{\mathrm{df}}$

(i) Necessarily, $x$ exists only if $y$ exists or has existed; and,

(ii) It's not the case that, necessarily, $y$ exists only if $x$ exists or has existed. (Ingram 2016: 2874)

The basic idea is, if $x$ depends on $y$-in the (temporal, asymmetric) non-rigid sense described by (NRD) - there's some time at which $x$ depends on $y$ for its existence. But this needn't continue to be so. A dependence relation may hold between $x$ and $y$ at some time, but the relation needn't always hold. If $x$ nonrigidly depends on $y$, then $x$ can't exist without $y$ having existed (at a time, i.e., the initial existence of $y$ ). So, there's a sense in which $x^{\prime}$ s existence is 'fixed' (or 'determined') by $y$ 's having existed, even though $y$ exists no longer $-x$ 's existence is guaranteed by the initial existence of $y$-and so we have a dependency that's not existence-entailing. ${ }^{16}$

Perhaps we can close our response with a challenge in the form of a question. We agreed with Bennett's stance against truth 'floating free'. We think this is what's often taken to motivate truth-making: the truths must depend. We agree with all that and we've explained our notions of dependence. They aren't existence-entailing, but so what? What have we missed that was integral? In the absence of an answer, there's no problem for us to face.

16. See also, Amie Thomasson (1999: 31-33), who discusses 'historical dependence' - another kind of existential dependence, which isn't existence-entailing, similar to the temporal non-rigid ontological dependence described here. 


\subsection{The Problem of Intuition}

Truth-maker theorists claim we have the intuition that truths depend. We agree. But they say more: they say truth must depend on what there is. Let's return to the quote from Armstrong:

My hope is that philosophers of realist inclinations will be immediately attracted to the idea that a truth, any truth, should depend for its truth upon something 'outside' it, in virtue of which it is true. (2004: 7)

Now, we've provided dependence. But we anticipate a reply. The truth-maker theorist has been clear all along. What they want isn't mere dependence. What concerns them is a specific form of dependence-what we may call 'upstanding dependence'. And upstanding dependence is existential. It connects truths to existing entities. Some forms of dependence-what we may call 'nefarious dependences' - aren't like that. They don't commit us to the existence of entities. So, what they want is upstanding dependence. We deliver nefarious dependence. $W e^{\prime}$ ve changed the question. Or so goes the imagined reply.

We aren't convinced by this for two related reasons. First, we don't think that our opponents are so immersed in thoughts of kinds of dependence. The various flavours we describe aren't explored in the truth-making literature. We don't think they've been considered at all. And whilst our opponent might have a knee-jerk "I didn't mean that kind of dependence" response, we'd like to see argument, not merely an off-the-cuff response, if the move is to be rejected. Second, and perhaps more usefully, we think we can make sense of what might motivate the thought that what matters is an upstanding form of dependence even within our nefarious picture. Returning to Bennett's insight, we take it we wish to avoid truth 'floating free'. We must ensure that truth is fixed by the world.

Of course, we take ourselves to deliver just that. In the case of true negative existentials, we say the world secures the truths. The world fixes or determines the truths. It does so via a nefarious dependence: a true negative existential proposition is true in virtue of the world not containing some entity or entities. In the presentist case, truths about the past are true in virtue of how the world was. Truths don't float free. The world fixes them all. But it does so via nefarious dependence; a non-existence-entailing form of dependence. We satisfy the demand for fixing. We satisfy the demand that truths depend upon something 'outside' themselves. We multiply the kinds of dependence being put to work, to be sure, but there's no obvious prohibition to our doing so, especially since the dependences are already out there in the world. 


\subsection{Alethic Pluralism?}

One last issue hovers into view. We say it's at least partly constitutive of truth's nature to depend. But we've also said there are many ways in which truth can depend. If there are many ways to depend, but it's nonetheless of truth's nature to depend, then it seems we're committed to saying there are different ways of being true. The claim that there are (many) ways of being true is a form of 'alethic pluralism'. In slogan form, the view that "there is more than one way for a proposition to be true" (Lynch 2004: 384). And to the extent that we say there's more than one way for a truth to depend, so (it might seem) we're obliged to say there's more than one way for propositions to be true. Why? Well, we say dependence can be realised in many ways. In that case, there's more than one way to partially constitute the nature of truth. And, so, there's more than one (total) nature of truth. Familiarly, there are concerns with pluralism. To the extent that our view is pluralistic, we are obliged to deal with those concerns. (Note, though, that we're not quite convinced that we really are committed to pluralism. Whilst we feel the pressure of the argument, and think we must say something in response, we're more tempted to say there are many different kinds of dependence, but only one kind of truth; we're pluralists about kinds of dependence, not about kinds of truth. The arguments we offer in this section are intended as a pre-emptive defence, in case we are forced into such a position as alethic pluralism.)

Now, of course, the problems facing (alethic) pluralism are many and varied - as are responses to them. We can't do justice to all the problems the view may face (nor, to be fair, can we say everything there is to be said about the advantages). The course we pursue is as follows. We begin by identifying a version of pluralism that we treat as our preferred version. Next, we introduce a problem that pluralism apparently faces, developed by Asay (2016). We then show how this problem can be overcome. We target this problem because it concerns the nature of truth. As above, we take ourselves to be making a claim about the nature of truth, and so it's essential to our position that we respond sensibly to concerns that centre on truth's alleged nature. Because of that, we won't say anything in response to more technical objections versions of pluralism are sometimes said to face. Whilst there may remain other problems for pluralism, none can be made on the basis of a claim about the nature of truth. To get things going, here's Asay, in his own words:

The pluralist advocates the existence of metaphysically potent alethic properties, and one should not, on grounds of ontological parsimony, posit such things unless there is sufficient reason to do so. My argument is that alethic properties do not earn their keep by way of truthmaking 
considerations, which seems to be their primary role on the pluralist's picture. Given that perfectly ontologically respectable entities are on hand to ground the truth of propositions, there is no need to look further to a set of alethic properties. Perhaps their existence is not in and of itself objectionable. Still, the issue is simply that they are an unnecessary posit, and so parsimony compels us to reject them. (2016: 8)

Why think this is so? Well, let's consider a case. Let us ask what makes true $<$ Samwise is brave $>$. Presumably, the story we tell will feature Sam and his bravery. It won't feature the pluralist's ('metaphysically potent') alethic property of truth. Thus, or so goes the thought, there's no reason here to posit a truth property.

Now, this may strike the reader as familiar. Structurally, the move Asay makes against the pluralist is strikingly similar to the move he makes against the proponent of a substantive truth property, viz., there's no role for the property of truth to play, which we considered in Section 2.2. Here, as there, we respond as follows: contra Asay, there is a reason to posit a property of truth. The truth property plays an explanatory, theoretical role. First, a truth property accounts for the resemblance of all the truths with regards their dependence. Second, we require a truth property in order to account for why truths depend. These are the distinctive theoretical roles the property plays. That being so, we see no metaphysical troubles with endorsing our particular approach (at least none that arise from concerns about alethic pluralism).

\section{Conclusion}

We've argued for a rejection of the truth-making orthodoxy: truths depend and that truths depend commits us to truth having a nature and it being of that nature to depend. But dependence itself is a flexible notion, admitting of many kinds. Because there are many kinds of dependence, there's no way to force a truth-maker objection on a view; we may simply review the dependences available.

\section{Acknowledgements}

An ancestor of this paper was presented at a Royal Institute of Philosophy seminar at the University of Nottingham in November 2016. We are grateful to the audience on that occasion and, in particular, we thank Stephen Barker, Craig French, and Mark Jago for especially helpful feedback. Some of the work on this paper was funded through the Centre for Philosophy of Time at the University 
of Milan; we gratefully acknowledge the financial support of the project 20150746 (15-5-3007000-601) by Fondazione Cariplo and Regione Lombardia. Special thanks to Giuliano Torrengo not only for securing the project funds and founding the Centre for Philosophy of Time, but for discussing with us many of the ideas developed in this paper.

\section{References}

Armstrong, David (1997). A World of States of Affairs. Cambridge University Press. https:// doi.org/10.1017/CBO9780511583308

Armstrong, David (2004). Truth and Truthmakers. Cambridge University Press. https:// doi.org/10.1017/CBO9780511487552

Armstrong, David (2005). Reply to Simons and Mumford. Australasian Journal of Philosophy, 83(2), 271-276. https://doi.org/10.1080/00048400500111196

Asay, Jamin (2014). Against Truth. Erkenntnis, 79(1), 147-164. https://doi.org/10.1007/ s10670-013-9483-y

Asay, Jamin (2016). Putting Pluralism in Its Place. Philosophy and Phenomenological Research. Advance online publication. doi:10.1111/phpr.12303 https://doi.org/10.1111/ phpr.12303

Barker, Stephen and Mark Jago (2012). Being Positive about Negative Facts. Philosophy and Phenomenological Research, 85(1), 117-138. https://doi.org/10.1111/j.19331592.2010.00479.x

Baron, Sam (2013). A Truthmaker Indispensability Argument. Synthese, 190(12), 24132427. https://doi.org/10.1007/s11229-011-9989-2

Beebee, Helen and Julian Dodd (2005). Introduction. In Helen Beebee and Julian Dodd (Eds.), Truthmakers (1-16). Oxford University Press. https://doi.org/10.1093/acprof:o so/9780199283569.003.0001

Bennett, Karen (2011). Truthmaking and Case-Making. Philosophy and Phenomenological Research, 83(1), 187-195. https://doi.org/10.1111/j.1933-1592.2011.00510.x

Bigelow, John (1988). The Reality of Numbers. Oxford University Press.

Bigelow, John (2009). Truthmakers and Truthbearers. In Robin Le Poidevin, Peter Simons, Andrew McGonigal, and Ross Cameron (Eds.), The Routledge Companion to Metaphysics (389-40o). Routledge. https://doi.org/10.4324/9780203879306.ch37

Cameron, Ross (2008a). How to Be a Truthmaker Maximalist. Noûs, 42(3), 410-421. https://doi.org/10.1111/j.1468-0068.2008.00687.x

Cameron, Ross (2008b). Truthmakers and Ontological Commitment: Or How to Deal with Complex Objects and Mathematical Ontology without Getting into Trouble. Philosophical Studies, 140(1), 1-18. https://doi.org/10.1007/s11098-008-9223-3

Cameron, Ross (2008c). Truthmakers, Realism and Ontology. Royal Institute of Philosophy Supplement, 62, 107-128. https://doi.org/10.1017/S135824610800060X

Cameron, Ross (2015). The Moving Spotlight. Oxford University Press. https://doi. org/10.1093/acprof:oso/9780198713296.001.0001

Cameron, Ross (in press). Truthmakers. In Michael Glanzberg (Ed.), The Oxford Handbook of Truth. Oxford University Press.

Daly, Chris (2005). So Where's the Explanation? In Helen Beebee and Julian Dodd (Eds.), 
Truthmakers (85-103). Oxford University Press. https://doi.org/10.1093/acprof:o so/9780199283569.003.0006

Diekemper, Joseph (2015). The Ontology of Thisness. Philosophy and Phenomenological Research, 90(1), 49-71. https://doi.org/10.1111/phpr.12010

Griffith, Aaron M. (2012). On Some Alleged Truthmakers for Negatives. Thought, 1(4), 301-308. https://doi.org/10.1002/tht3.52

Griffith, Aaron M. (2014). Truthmaking and Grounding. Inquiry, 57(2), 196-215. https:// doi.org/10.1080/0020174X.2013.855655

Griffith, Aaron M. (2015a). How Negative Truths Are Made True. Synthese, 192(1), 317335. https://doi.org/10.1007/s11229-014-0570-7

Griffith, Aaron M. (2015b). Towards a Pluralist Theory of Truthmaking. Erkenntnis, 8o(6), 1157-1173. https://doi.org/10.1007/s10670-014-9717-7

Heil, John (2003). From an Ontological Point of View. Oxford University Press. https://doi. org/10.1093/0199259747.001.0001

Ingram, David (2016). The Virtues of Thisness Presentism. Philosophical Studies, 173(11), 2867-2888. https://doi.org/10.1007/s11098-016-0641-3

Kitamura, Naoaki (2014). Is Any Alleged Truthmaker for Negatives Explanatorily Deficient? Thought, 3(3), 200-207. https://doi.org/10.1002/tht3.129

Koslicki, Kathrin (2012). Varieties of Ontological Dependence. In Fabrice Correia and Benjamin Schnieder (Eds.), Metaphysical Grounding (186-213). Cambridge University Press. https://doi.org/10.1017/CBO9781139149136.008

Koslicki, Kathrin (2013). Ontological Dependence: An Opinionated Survey. In Benjamin Schnieder, Miguel Hoeltje, and Alex Steinberg (Eds.), Varieties of Dependence (31-64). Philosophia Verlag.

Kukso, Boris (2006). The Reality of Absences. Australasian Journal of Philosophy, 84(1), 2137. https://doi.org/10.1080/00048400600571679

Lewis, David (2001). Forget about the "Correspondence Theory of Truth". Analysis, 61(4), 275-280. https://doi.org/10.1093/analys/61.4.275

Lowe, E. Jonathan (1998). The Possibility of Metaphysics. Oxford University Press. https:// doi.org/10.1093/0199244995.001.0001

Lowe, E. Jonathan (2006). The Four-Category Ontology. Oxford University Press. https:// doi.org/10.1093/0199254397.001.0001

Lowe, E. Jonathan (2010). Ontological Dependence. In Edward N. Zalta (Ed.), The Stanford Encyclopedia of Philosophy (Spring 2010). Retrieved from http://plato.stanford. edu/archives/spr201o/entries/dependence-ontological/

Lowe, E. Jonathan (2012). Against Monism. In Philip Goff (Ed.), Spinoza on Monism (99122). Palgrave MacMillan.

Lowe, E. Jonathan (2013). Some Varieties of Metaphysical Dependence. In Benjamin Schnieder, Miguel Hoeltje, and Alex Steinberg (Eds.), Varieties of Dependence (193210). Philosophia Verlag.

Lynch, Michael (2004). Truth and Multiple Realizability. Australasian Journal of Philosophy, 82(3), 384-408. https://doi.org/10.1080/713659875

Martin, Charles B. (1996). How It Is: Entities, Absences and Voids. Australasian Journal of Philosophy, 74(1), 57-65. https://doi.org/10.1080/00048409612347061

McFetridge, Ian (1990). Truth, Correspondence, Explanation, and Knowledge. In John Haldane and Roger Scruton (Eds.), Logical Necessity and Other Essays (29-52). Aristotelian Society. 
McGrath, Matthew (2003). What the Deflationist May Say about Truthmaking. Philosophy and Phenomenological Research, 66(3), 666-688. https://doi.org/10.1111/j.1933-1592.2003. tb00283.x

Melia, Joseph (2005). Truthmaking without Truthmakers. In Helen Beebee and Julian Dodd (Eds.), Truthmakers (67-84). Oxford University Press. https://doi.org/10.1093/ acprof:oso/9780199283569.003.0005

Merricks, Trenton (2007). Truth and Ontology. Oxford University Press. https://doi. org/10.1093/acprof:oso/9780199205233.001.0001

Molnar, George (2000). Truthmakers for Negative Truths. Australasian Journal of Philosophy, 78(1), 72-86. https://doi.org/10.1080/00048400012349361

Rodriguez-Pereyra, Gonzalo (2000). What Is the Problem of Universals? Mind, 109(434), 255-273. https://doi.org/10.1093/mind/109.434.255

Rodriguez-Pereyra, Gonzalo (2005). Why Truthmakers? In Helen Beebee and Julian Dodd (Eds.), Truthmakers (17-32). Oxford University Press. https://doi.org/10.1093/ acprof:oso/9780199283569.003.0002

Schaffer, Jonathan (2010). Monism: The Priority of the Whole. Philosophical Review, 119(1), 31-76. https://doi.org/10.1215/00318108-2009-025

Schulte, Peter (2011). Truthmakers: A Tale of Two Explanatory Projects. Synthese, 181(3), 413-431. https://doi.org/10.1007/s11229-010-9716-4

Sider, Theodore (2001). Four-Dimensionalism. Oxford University Press. https://doi. org/10.1093/019924443X.001.0001

Tallant, Jonathan (2009). Ontological Cheats Might Just Prosper. Analysis, 69(3), 422-430. https://doi.org/10.1093/analys/anp077

Tallant, Jonathan (2013). Problems of Parthood for Proponents of Priority. Analysis, 73(3), 429-438. https://doi.org/10.1093/analys/ant045

Tallant, Jonathan (2015). Ontological Dependence in a Space-Time World. Philosophical Studies, 172(11), 3101-3118. https://doi.org/10.1007/s11098-015-0459-4

Tallant, Jonathan and David Ingram (2015). Nefarious Presentism. The Philosophical Quarterly, 65(260), 355-371. https://doi.org/10.1093/pq/pqu095

Thomasson, Amie L. (1999). Fiction and Metaphysics. Cambridge University Press. https:// doi.org/10.1017/CBO9780511527463 